\title{
Syntheses and properties of copolymers containing indolocarbazole moiety in the side chain
}

\author{
Masaji Akimoto ${ }^{1}$, Tatsuya Kawano ${ }^{2}$, Yuta Iwasawa ${ }^{2}$, Yusuke Takahashi ${ }^{2}$, Kazuki Yamashita ${ }^{2}$, Masuki Kawamoto ${ }^{3}$ \\ and Yu Nagase ${ }^{1,2}$ \\ Novel copolymers containing the indolo[3,2-b]carbazole (INC) moiety were synthesized, and the effects of the INC content \\ on their physical properties were investigated. The homopolymer of the INC-containing monomer, 1-octyl-7-(4-vinylbenzyl) \\ indolo[3,2-b]carbazole and copolymers with styrene were prepared by radical polymerization. Four kinds of copolymers with \\ different compositions were obtained. The glass transition temperatures (Tgs) were observed in the range of $101-112{ }^{\circ} \mathrm{C}$, and \\ the decomposition temperatures were nearly $400{ }^{\circ} \mathrm{C}$. The photonic properties of the copolymers were also evaluated in solution \\ in tetrahydrofuran and for spin-coated films on a fused silica substrate. In the ultraviolet-visible absorption spectra, maximum \\ absorption peaks were observed at $\mathbf{3 4 0}-345 \mathrm{~nm}$ in both the solutions and the films. In the case of the solutions, the \\ photoluminescence intensities of the copolymers increased with increasing INC monomer units in the copolymer. On the \\ contrary, the photoluminescence intensities of the copolymer films decreased with increasing INC content in the copolymer, \\ which is likely due to the concentration quenching caused by the condensation of intermolecular interactions derived from INC \\ components. The copolymer with a low content of the INC moiety exhibited high emission and good film-forming ability. \\ Polymer Journal (2011) 43, 959-965; doi:10.1038/pj.2011.102
}

Keywords: fluorescence; indolocarbazole; polystyrene; radical copolymerization

\section{INTRODUCTION}

Recently, interest in organic compounds for electronic and photonic materials has increased greatly due to their utility as active components in a number of electronic devices, such as electroluminescence devices, light-emitting diodes and field-effect transistors. ${ }^{1-7}$ In particular, organic compounds that possess a $\pi$-conjugated system, such as pentacene and oligothiophene, have attracted much attention ${ }^{8-13}$ because of their mechanical properties, low cost and variety of photonic properties obtained by chemical modification. Therefore, significant progress has been made in the study of $\pi$-conjugated organic compounds, which might be competitive with amorphous silicon in electronic and photonic devices. Although there are some $\pi$-conjugated organic compounds that exhibit higher charge carrier mobility than amorphous silicon, $\pi$-conjugated organic compounds have not been used commercially because they are easily oxidized under ambient conditions and lack solubility and photonic stability. According to the relatively high HOMO level and the low band gap, most $\pi$-conjugated organic compounds are easily photo-oxidized, resulting in the degradation of electronic characteristics when their films are processed in air or used in ambient conditions. ${ }^{14,15}$

Thus, we attempted to synthesize a novel $\pi$-conjugated organic compound that exhibits satisfactory photonic performance with good thermal stability and processability. In this study, we focused on indolo[3,2- $b]$ carbazole (INC), which possesses a conjugated structure and a relatively low HOMO level. INC is known to show strong blue fluorescence under irradiation by ultraviolet (UV) light. In recent years, there have been some reports on the preparation and characterization of derivatives of INC. ${ }^{16-25}$ In particular, Hu et al. ${ }^{21}$ have reported 1,7-dinaphtylindolo[3,2-b]carbazole, which showed excellent hole-transport properties in light-emitting diodes. Later, the first organic field-effect transistors using $N$-alkylated INC as an active layer was successfully fabricated. ${ }^{16}$ In addition, there have also been some reports on polymers containing the INC moiety. ${ }^{26-29}$ For example, Li et al. ${ }^{15}$ synthesized a new class of polyindolocarbazole via the coupling polymerization of 2,8-dichloroindolo[3,2-b] carbazole derivatives, a film of which could be manufactured by spin coating and exhibited a field-effect transistor mobility of $0.02 \mathrm{~cm}^{2} \mathrm{~V}^{-1} \mathrm{~s}^{-1}$. However, INC derivatives have drawbacks, including poor solubility in organic solvents and a lack of chemical stability.

In our previous work, the solubility of INC was improved by the alkylation of the $\mathrm{N}$-position of INC with relatively long alkyl groups. ${ }^{30}$ It was found that the photonic properties, such as ultraviolet-visible absorption and the photoluminescence spectra of $\mathrm{N}$-alkylated INC, were similar to those of INC, and the photoluminescence quantum

${ }^{1}$ Course of Science and Technology, Graduate School of Science and Technology, Tokai University, Kanagawa, Japan; ${ }^{2}$ Department of Applied Chemistry, Graduate School of Engineering, Tokai University, Kanagawa, Japan and ${ }^{3}$ RIKEN, 2-1 Hirosawa, Saitama, Japan

Correspondence: Professor Y Nagase, Department of Applied Chemistry, Graduate School of Engineering, Tokai University, 4-1-1 Kitakaname, Hiratsuka, Kanagawa 259-1292, Japan. 
yield of $N$-alkylated INC was $0.52-0.54$. To investigate the fundamental characteristics of the INC moiety in the polymer, we designed a novel $N$-substituted monomer based on the INC moiety. In this paper, the introduction of alkyl and 4-vinylbenzyl groups at the $\mathrm{N}$-positions of INC was carried out to produce an INC-containing vinyl monomer, 1-alkyl-7-(4-vinylbenzyl)indolo[3,2-b]carbazole. Using this new monomer, the homopolymer and copolymers with styrene were prepared by radical polymerization to obtain styrenetype polymers containing the INC moiety as a side chain. Furthermore, the thermal and photonic properties of the polymers obtained were investigated to determine the thermal and photonic performance of INC-containing polymers.

\section{MATERIALS AND METHODS}

\section{Materials}

INC was prepared by the procedure reported by Bergman. ${ }^{31}$ Di-tert-butyl dicarbonate and 1-iodooctane were purchased from Tokyo Chemical Industry (Tokyo, Japan). p-Chloromethylstyrene was provided gratis from Seimi Chemical (Kanagawa, Japan). A solution of 60\%-sodium hydride in oil was purchased from Sigma-Aldrich (Tokyo, Japan) and used as received. A 1.6-M hexane solution of butyllithium, 4-(N,N-dimethylamino)pyridine and ammonium chloride were purchased from Wako Pure Chemical Industries (Kanagawa, Japan). Tetrahydrofuran (THF) was distilled over sodium to remove any water present. Anhydrous dimethylformamide and 1-methyl2-pyrrolidinone (NMP) were purchased from Sigma-Aldrich. The radical initiator, $2,2^{\prime}$-azobis(isobutyronitrile), was purified by recrystallization from ethanol.

Synthesis of 1,7-di-tert-butyloxycarbonylindolo[3,2-b]carbozole (1) Under an argon atmosphere, INC $(10.0 \mathrm{~g}, 39.0 \mathrm{mmol})$ was dissolved in $625 \mathrm{ml}$ of THF. Then, di-tert-butyl dicarbonate $(18.7 \mathrm{~g}, 85.7 \mathrm{mmol})$ and 4 -(N,N-dimethylamino)pyridine $(1.04 \mathrm{~g}, 8.58 \mathrm{mmol})$ were added to this solution. The mixture was stirred at room temperature for $12 \mathrm{~h}$. After the solvent was evaporated, the crude product was washed with $200 \mathrm{ml}$ of ethyl acetate to obtain $13.3 \mathrm{~g}$ of compound $\mathbf{1}$ as a white powder. Yield: $74.7 \%$.

${ }^{1} \mathrm{H}-\mathrm{NMR} \quad \delta\left(400 \mathrm{MHz}, \mathrm{CDCl}_{3}\right.$, p.p.m.): $1.83(18 \mathrm{H}$, s), $7.38(2 \mathrm{H}, \mathrm{t}$, $J=7.32 \mathrm{~Hz}), 7.48(2 \mathrm{H}, \mathrm{t}, J=7.31 \mathrm{~Hz}), 8.08(2 \mathrm{H}, \mathrm{d}, J=7.32 \mathrm{~Hz}), 8.30(2 \mathrm{H}, \mathrm{d}$, $J=7.30 \mathrm{~Hz}), 8.94(2 \mathrm{H}, \mathrm{s})$.

Infrared (IR), $v\left(\mathrm{KBr}, \mathrm{cm}^{-1}\right): 2977,1720(\mathrm{C}=\mathrm{O}), 1481,1434,1373,1303$, $1238,1149,1049,879,844,748$.

Synthesis of 1-tert-butyloxycarbonylindolo [3,2-b]carbazole (2) Under an argon atmosphere, compound $\mathbf{1}(5.0 \mathrm{~g}, 11.0 \mathrm{mmol})$ was dissolved in $185 \mathrm{ml}$ of THF, and the solution was cooled at $0{ }^{\circ} \mathrm{C}$. Then, $20.6 \mathrm{ml}$ of $1.6 \mathrm{M}$ hexane solution of butyllithium $(20.6 \mathrm{ml}, 32.9 \mathrm{mmol})$ was slowly added to this solution. After the reaction mixture was stirred for $1 \mathrm{~h}$, the mixture was quenched with a saturated aqueous solution of ammonium chloride and extracted with chloroform. The solvent was removed under reduced pressure, and the product was washed with an excess amount of acetone to obtain $2.60 \mathrm{~g}$ of compound 2 as a white powder. Yield: $67.4 \%$.

${ }^{1} \mathrm{H}-\mathrm{NMR} \delta\left(400 \mathrm{MHz}, \mathrm{CDCl}_{3}\right.$, p.p.m.): $1.84(9 \mathrm{H}, \mathrm{s}), 7.36(1 \mathrm{H}, \mathrm{t}, J=7.32 \mathrm{~Hz})$, 7.42-7.52 (3H, m), $7.93(1 \mathrm{H}, \mathrm{s}), 8.03(1 \mathrm{H}, \mathrm{d}, J=6.83 \mathrm{~Hz}), 8.09(1 \mathrm{H}, \mathrm{s}), 8.16$ $(1 \mathrm{H}, \mathrm{d}, J=7.81 \mathrm{~Hz}), 8.31(1 \mathrm{H}, J=7.81 \mathrm{~Hz}), 9.05(1 \mathrm{H}, \mathrm{s})$.

IR, $v\left(\mathrm{KBr}, \mathrm{cm}^{-1}\right): 3417(\mathrm{~N}-\mathrm{H}), 2970,1724(\mathrm{C}=\mathrm{O}), 1612,1515,1442,1357$, $1311,1149,844,763,744$.

\section{Synthesis of 1-tert-butyloxycarbonyl-7-octyl-indolo}

\section{$[3,2-b]$ carbazole (3)}

Under an argon atmosphere, compound 2 (10.0 g, $28.1 \mathrm{mmol})$ was dissolved in $446 \mathrm{ml}$ of dichloromethane, and $59 \mathrm{ml}$ of $50 \% \mathrm{NaOH}$ aqueous solution, tetrabutylammonium iodide $(2.1 \mathrm{~g}, 5.69 \mathrm{mmol})$ and 1 -iodooctane $(40.4 \mathrm{~g}$, $16.8 \mathrm{mmol}$ ) were added to this solution. After it was stirred at room temperature for $22 \mathrm{~h}$, the solution was extracted with chloroform, and the solvent was removed under reduced pressure. The product was purified by column chromatography on silica gel with hexane and chloroform to obtain $11.2 \mathrm{~g}$ of compound 3 as a yellow viscous liquid. Yield: $83.2 \%$.

${ }^{1} \mathrm{H}-\mathrm{NMR} \delta\left(400 \mathrm{MHz}, \mathrm{DMSO}-\mathrm{d}_{6}\right.$, p.p.m.): $0.78(3 \mathrm{H}, \mathrm{t}, J=6.34 \mathrm{~Hz}), 1.08-$ $1.45(10 \mathrm{H}, \mathrm{m}), 1.69-2.02(11 \mathrm{H}, \mathrm{m}), 4.48(2 \mathrm{H}, \mathrm{t}, J=6.83 \mathrm{~Hz}), 7.23(1 \mathrm{H}, \mathrm{t}$, $J=7.32 \mathrm{~Hz}), 7.47-7.54(2 \mathrm{H}, \mathrm{m}), 7.61(1 \mathrm{H}, \mathrm{d}, J=8.29 \mathrm{~Hz}), 8.19(1 \mathrm{H}, \mathrm{d}$, $J=7.81 \mathrm{~Hz}), 8.26(1 \mathrm{H}, \mathrm{d}, J=8.29 \mathrm{~Hz}), 8.32(1 \mathrm{H}, \mathrm{d}, J=7.32 \mathrm{~Hz}), 8.38(1 \mathrm{H}, \mathrm{s})$, $8.96(1 \mathrm{H}, \mathrm{s})$

IR, $v\left(\mathrm{KBr}, \mathrm{cm}^{-1}\right): 2920,1720(\mathrm{C}=\mathrm{O}), 1508,1442,1369,1303,1149,1026$, 829,744 .

\section{Synthesis of 1-octylindolo[3,2-b]carbazole (4)}

Under an argon atmosphere, compound $3(9.19 \mathrm{~g}, 19.6 \mathrm{mmol})$ was heated with stirring at $150{ }^{\circ} \mathrm{C}$ for $96 \mathrm{~h}$. Then, the product was purified by recrystallization with ethyl acetate to obtain $6.32 \mathrm{~g}$ of compound 4 as a pale yellow powder. Yield: $87.6 \%$.

${ }^{1} \mathrm{H}-\mathrm{NMR} \delta\left(400 \mathrm{MHz}, \mathrm{DMSO}-\mathrm{d}_{6}\right.$, p.p.m.): $0.78(3 \mathrm{H}, \mathrm{t}, J=6.76 \mathrm{~Hz}), 1.19$ $1.24(6 \mathrm{H}, \mathrm{m}), 1.31-1.36(4 \mathrm{H}, \mathrm{m}), 1.83-1.86(2 \mathrm{H}, \mathrm{m}), 4.42(2 \mathrm{H}, \mathrm{t}, J=6.84 \mathrm{~Hz})$, $7.14-7.18(2 \mathrm{H}, \mathrm{m}), 7.36(1 \mathrm{H}, \mathrm{t}, J=7.39 \mathrm{~Hz}), 7.42(1 \mathrm{H}, \mathrm{t}, J=7.57 \mathrm{~Hz}), 7.45(1 \mathrm{H}$, d, $J=7.88 \mathrm{~Hz}), 7.53(1 \mathrm{H}, \mathrm{d}, J=8.33 \mathrm{~Hz}), 8.13(1 \mathrm{H}, \mathrm{s}), 8.21-8.23(2 \mathrm{H}, \mathrm{m}), 8.24$ $(1 \mathrm{H}, \mathrm{s}), 11.06(1 \mathrm{H}, \mathrm{s})$.

IR, $v\left(\mathrm{KBr}, \mathrm{cm}^{-1}\right): 3402(\mathrm{~N}-\mathrm{H}), 2923,2341,1508,1458,1323,1245,840,744$.

Synthesis of 1-octyl-7-(4-vinylbenzyl) indolo[3,2-b]carbazole (5) Under an argon atmosphere, sodium hydride $(60 \% \mathrm{NaH}$ in oil, $0.816 \mathrm{~g}$, $20.4 \mathrm{mmol}$ ) was dispersed in $68 \mathrm{ml}$ of dimethylformamide, and the mixture was stirred at $0{ }^{\circ} \mathrm{C}$ for $30 \mathrm{~min}$. Compound $4(5.0 \mathrm{~g}, 13.6 \mathrm{mmol})$ was added to this solution, and the mixture was stirred at $0^{\circ} \mathrm{C}$ for $30 \mathrm{~min}$. After p-chloromethylstyrene $(3.11 \mathrm{~g}, 20.4 \mathrm{mmol})$ was added to this solution, it was stirred at $70{ }^{\circ} \mathrm{C}$ for $24 \mathrm{~h}$. Then, the reaction mixture was poured into 21 of methanol to obtain the crude product. The product was purified by recrystallization with ethanol and chloroform to yield $4.88 \mathrm{~g}$ of the monomer compound 5 as a pale yellow powder. Yield: $74.1 \%$.

${ }^{1} \mathrm{H}-\mathrm{NMR} \delta\left(400 \mathrm{MHz}, \mathrm{DMSO}-\mathrm{d}_{6}\right.$, p.p.m.): $0.79(3 \mathrm{H}, \mathrm{t}, J=6.83 \mathrm{~Hz}), 1.18$ $1.32(10 \mathrm{H}, \mathrm{m}), 1.83(2 \mathrm{H}, \mathrm{t}, J=6.83 \mathrm{~Hz}), 4.46(2 \mathrm{H}, \mathrm{t}, J=6.83 \mathrm{~Hz}), 5.16(1 \mathrm{H}, \mathrm{d}$, $J=11.2 \mathrm{~Hz}), 5.69(1 \mathrm{H}, \mathrm{d}), 5.73(2 \mathrm{H}, \mathrm{s}), 6.59-6.66(1 \mathrm{H}, \mathrm{m}), 7.13-7.21(4 \mathrm{H}, \mathrm{m})$, $7.35(2 \mathrm{H}, \mathrm{d}, J=8.29 \mathrm{~Hz}), 7.39-7.44(2 \mathrm{H}, \mathrm{m}), 7.56(2 \mathrm{H}, \mathrm{d}, J=8.29 \mathrm{~Hz}), 8.19(1 \mathrm{H}$, d, $J=7.31 \mathrm{~Hz}), 8.29(1 \mathrm{H}, \mathrm{d}, J=7.31 \mathrm{~Hz}), 8.34(1 \mathrm{H}, \mathrm{s}), 8.35(1 \mathrm{H}, \mathrm{s})$.

IR, $v\left(\mathrm{KBr}, \mathrm{cm}^{-1}\right): 3051,2923,2854,1612,1508,1465,1326,840,740$.

Preparation of the homopolymer containing the INC moiety (HP) Under an argon atmosphere, compound $5(3.00 \mathrm{~g}, 6.2 \mathrm{mmol})$ was dissolved in $10 \mathrm{ml}$ of NMP, and 2,2'-azobis(isobutyronitrile) $(0.03 \mathrm{~g}, 0.18 \mathrm{mmol})$ was added to this solution. Then, the mixture was stirred at $60^{\circ} \mathrm{C}$ overnight. The reaction mixture was poured into an excess amount of methanol to precipitate the polymer. The reprecipitation was carried out by pouring the NMP solution into excess methanol to obtain $2.48 \mathrm{~g}$ of $\mathbf{H P}$ as a pale yellow powder. Yield: $82.7 \%$.

IR, $v\left(\mathrm{KBr}, \mathrm{cm}^{-1}\right): 3024,2923,2850,1612,1577,1466,1323,1111,1007,829$, 741,687

Preparation of copolymers containing the INC moiety (CP1-CP4) The similar polymerizations were carried out for the mixtures of monomer compound $\mathbf{5}$ and styrene to prepare copolymers, CP1-CP4, with different compositions of monomer units. The typical procedure is described below.

Under an argon atmosphere, compound $5(2.8 \mathrm{~g}, 5.78 \mathrm{mmol})$ and styrene $(0.20 \mathrm{~g}, 1.9 \mathrm{mmol})$ were dissolved in $7.7 \mathrm{ml}$ of NMP, and $2,2^{\prime}$-azobis(isobutyronitrile) ( $0.03 \mathrm{~g}, 0.18 \mathrm{mmol})$ was added to this solution. Then, the mixture was stirred at $60^{\circ} \mathrm{C}$ overnight. The reaction mixture was poured into an excess amount of methanol to precipitate the polymer. The reprecipitation was carried out from the NMP solution into excess methanol to obtain $2.34 \mathrm{~g}$ of CP1 as a pale yellow powder. Yield: $78.1 \%$.

IR, $v\left(\mathrm{KBr}, \mathrm{cm}^{-1}\right): 3024,2924,1612,1508,1466,1323,1007,880,833$, 740,698 .

\section{Preparations of coating films}

The coating polymer films were prepared by spin coating $1.0 \mathrm{wt} . \%$ polymer solutions dissolved in chloroform onto a fused silica substrate at $1000 \mathrm{rpm}$. The 
thickness of the coated polymer films was measured with a Dektak surface profiler, SLOAN DEKTAK IIA (Veeco Co., Plainview, NY, USA).

\section{Characterizations}

${ }^{1} \mathrm{H}-\mathrm{NMR}$ spectroscopy was conducted with a JEOL NM-TH5SK $400 \mathrm{MHz}$ Fourier-Transform-NMR (JEOL Ltd., Tokyo, Japan), and the chemical shifts were estimated in parts per million with tetramethylsilane as an internal standard. IR spectra were recorded with a Shimadzu FTIR-8400 spectrometer (Shimadzu Co., Kyoto, Japan). The molecular weights of the polymers were determined with a Tosoh gel permeation chromatography system (Tosoh Co., Tokyo, Japan) equipped with four columns of TSK gels and a refractive index detector, RI-8010, using THF as an eluent. The elution was detected by both refractive index and laser light scattering detectors using the Tosoh LS-8000 to determine the absolute molecular weight. Standard polystyrenes were used to calibrate the molecular weights. Differential scanning calorimetry and thermal gravimetric analysis were carried out on Seiko Instruments DSC-6200 and TG/ DTA-6200 (Seiko Instruments Inc., Chiba, Japan), respectively, at a heating rate of $10^{\circ} \mathrm{C} / \mathrm{min}$ under a nitrogen atmosphere. Ultraviolet-visible adsorption and photoluminescence spectra were conducted with a JEOL V-530 and SHIMADZU RF-5300PC, respectively.

\section{RESULTS AND DISCUSSION}

\section{Preparation of the INC-containing monomer}

The starting INC was prepared according to the literature, ${ }^{31}$ via a cyclization reaction of $\mathrm{di}(1 \mathrm{H}-\mathrm{indol}-3-\mathrm{yl})$ methane obtained from indole and formaldehyde by the Mannich reaction. In our previous paper, ${ }^{30}$ 1-octyl-7-(4-vinylbenzyl)indolo[3,2-b]carbazole (5) was prepared as a monomer compound by a reaction of 1 -iodooctane with the INC anion derived from the reaction of INC with sodium hydride, followed by the addition of $p$-chloromethylstyrene. However, the yield of monomer $\mathbf{5}$ was very low because the mono-alkylation of the $\mathrm{N}$ position of INC proceeded with a large amount of byproduct, dialkylated INC, and so on. Therefore, we investigated a new synthetic route to prepare monomer $\mathbf{5}$, as shown in Scheme 1 . At first, both $\mathrm{N}$ positions of INC were protected by a tert-butyloxycarbonyl (Boc) group; then, the deprotection of one of the Boc groups was easily achieved by a reaction with $n$-butyllithium at $0{ }^{\circ} \mathrm{C}$ to obtain compound 2, which has been described in the literature. ${ }^{32}$ After the alkylation of 2 through the reaction with $\mathrm{NaH}$ and 1-iodooctane, the deprotection of $\mathbf{3}$ was carried out by a reaction with sulfuric acid to obtain mono-alkylated INC, 4 , with high yield. Finally, the reaction of 4 with $\mathrm{NaH}$ and $p$-chloromethylstyrene gave the desired monomer, $\mathbf{5}$, with high yield.

\section{Preparation of the INC-containing polymers and their thermal properties}

The homopolymer of the INC-containing monomer, 5, and the copolymers with styrene were prepared by radical polymerization, as shown in Scheme 2. The results of the polymerizations are summarized in Table 1 with their thermal properties. All of the polymers in this table were soluble in toluene, chloroform, THF and NMP but insoluble in methanol.

In the copolymerization, the molar ratio of monomer $\mathbf{5}$ and styrene was fixed at 75/25, 50/50, 25/75 and 5/95 to obtain four copolymers with different compositions. The compositions of the copolymers, $x / y$, could not be determined exactly because the broad peaks of phenylene protons were observed in their ${ }^{1} \mathrm{H}-\mathrm{NMR}$ spectra. Interestingly, the absolute weight-average molecular weights $\left(\mathrm{Mw}^{\star}\right)$ of these polymers, which were determined by laser light scattering, were higher than the values of $M \mathrm{w}$ determined by gel permeation chromatography measurements, as listed in Table 1. It is assumed that the interaction of the INC moiety was very strong, and thus the molecular size of the polymer was compact in the solution. As a result, a lower $M \mathrm{w}$ than the absolute $M \mathrm{w}^{*}$ was observed in the gel permeation chromatography measurements.

The thermal properties of the polymers were evaluated by differential scanning calorimetry and thermal gravimetric analysis. According to the differential scanning calorimetry curves shown in Figure 1, the Tgs of the copolymers increased with increasing INC content, and the $T \mathrm{~g}$ of homopolymer of $\mathbf{5}, \mathbf{H P}$, was clearly higher than that of polystyrene. This result suggests that the molecular interaction

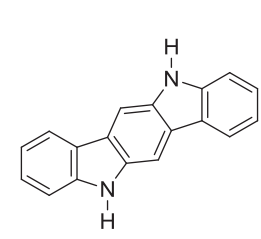

INC

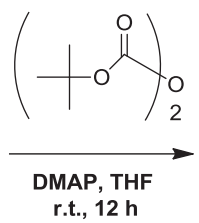

r.t., $12 \mathrm{~h}$

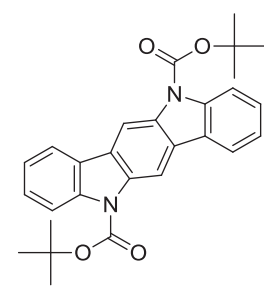

1

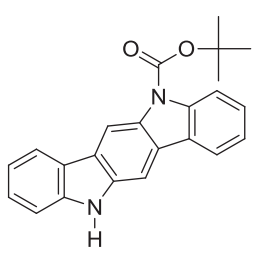

2

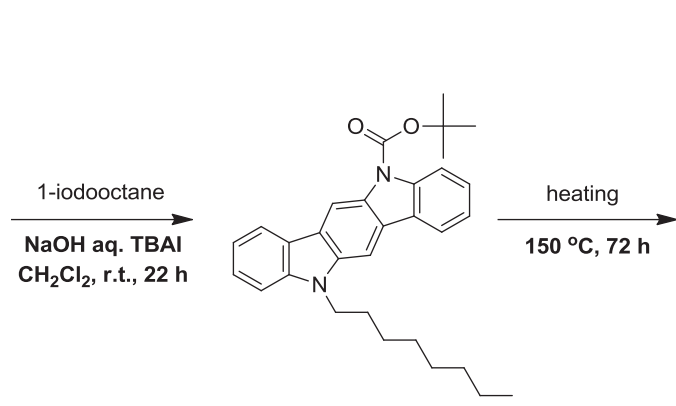

3

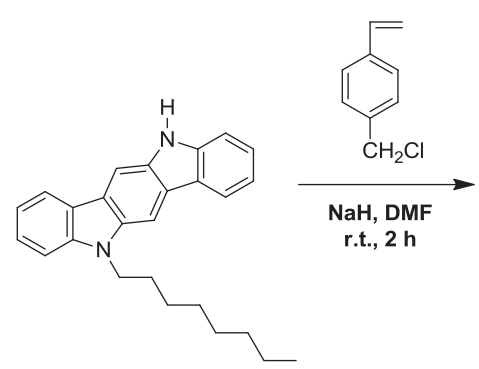

4

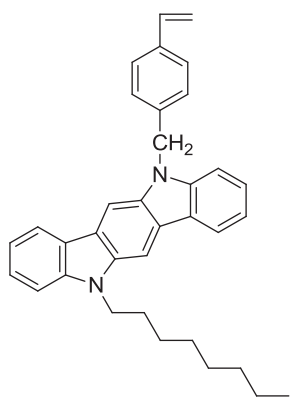

5

Scheme 1 Synthesis of the indolo[3,2-b]carbazole-containing monomer. 


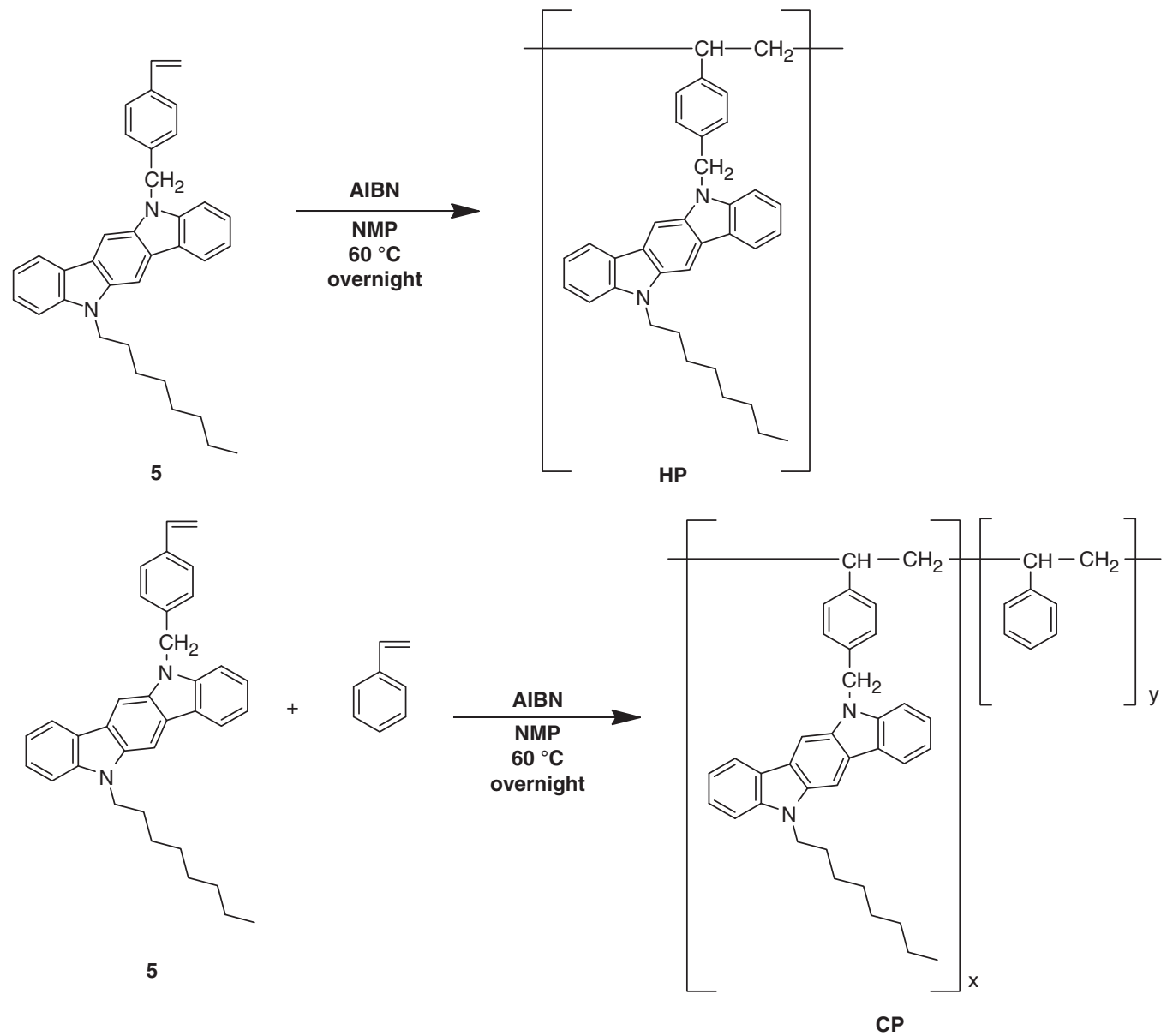

Scheme 2 Preparation of the indolo[3,2-b]carbazole-containing homopolymer and copolymers.

due to $\pi$-stacking between the INC moieties was stronger than that between styrene units, and thus the Tgs of the polymers were higher than that of polystyrene. Moreover, the $10 \%$ decomposition temperatures, $T_{\mathrm{d} 10}$, of these polymers were nearly $400^{\circ} \mathrm{C}$, as shown in Table 1 and Figure 2. Interestingly, the degradation temperatures of $\mathbf{H P}$ and copolymers CP1-4 were higher than that of polystyrene. Therefore, these INC-containing polymers exhibited relatively high thermal stabilities. In addition, as shown in Figure 3, the X-ray diffraction patterns of the polymers exhibited broad peaks, which suggests that all of the polymers were in the amorphous state.

\section{Photonic properties of the polymers}

The photonic properties of the polymers were evaluated in solutions of THF and films. The polymer thin films were prepared by spin coating onto fused silica substrates. The thicknesses of the HP, CP1, CP2, CP3 and CP4 films were 161, 148, 143, 149 and $149 \mathrm{~nm}$, respectively, which were determined using a Dektak surface profiler. Figures 4 and 5 show the ultraviolet-visible absorption spectra of the copolymers in their solutions and films, respectively. The maximum absorption peaks of the polymer solutions were observed at 340$342 \mathrm{~nm}$, whereas those of films were $344-345 \mathrm{~nm}$. Therefore, the maximum absorptions of the films were slightly shifted to longer wavelengths than those of the solutions. In addition, the peak intensity decreased with decreasing INC content of the copolymers. From the results of Figure 4, the actual compositions of copolymers were estimated from the maximum peak intensities $(341 \mathrm{~nm})$ of the copolymers in comparison with that of the homopolymer, HP. As a result, the actual compositions (x/y) of CP1, CP2, CP3 and CP4 were estimated to be $85 / 15,66 / 34,56 / 44$ and $35 / 65$ wt.\%, respectively. The weight ratios of monomer 5 to styrene of CP1, CP2, CP3 and CP4 after copolymerization were calculated to be $93 / 7,82 / 18,61 / 39$ and $20 / 80$ wt.\%, respectively, from the molar ratios listed in Table 1 . Therefore, it was found that the copolymer compositions were not in agreement with the ratio of monomer $\mathbf{5}$ and styrene in the copolymerization due to the difference in monomer reactivity between monomer $\mathbf{5}$ and styrene in the radical copolymerization, where the yields of the copolymers were in the range of $70-80 \%$.

The photoluminescence spectra in the polymer solutions and the films are shown in Figures 6 and 7. In the case of the solutions, the photoluminescence intensities of the copolymers were in the order of CP1 $>\mathbf{C P 2}>\mathbf{C P 3}>\mathbf{C P 4}$, which is essentially the same order as the INC content. Therefore, the photoluminescence behavior of these copolymers must be derived from the INC moiety. It was also confirmed that the homopolymer of 5, HP, exhibited a luminescence pattern similar to those of the copolymers.

On the contrary, as shown in Figure 7 , the photoluminescence intensities of the copolymer films were in the order of CP4 $>$ CP3 $>$ CP2 $>$ CP1, which is the opposite order of the INC content, and the HP film exhibited the lowest peak intensity. Further- 
Table 1 Results of polymerizations and thermal property of the polymers

\begin{tabular}{|c|c|c|c|c|c|c|}
\hline Code & 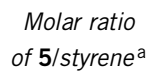 & $M w \times 10^{-4 b}$ & $M w / M n^{b}$ & $\begin{array}{l}M w^{*} \times 10^{-4} \\
(\text { by } L A L L S)^{\mathrm{c}}\end{array}$ & $\operatorname{Tg} / C^{d}$ & $T d_{10} /{ }^{\circ} C^{\mathrm{e}}$ \\
\hline $\mathrm{HP}$ & $100 / 0$ & 12.6 & 5.52 & 87.6 & 121 & 420 \\
\hline CP1 & $75 / 25$ & 6.28 & 3.16 & 34.8 & 112 & 413 \\
\hline CP2 & $50 / 50$ & 4.15 & 2.12 & 21.8 & 107 & 409 \\
\hline CP3 & $25 / 75$ & 2.45 & 1.94 & 14.8 & 104 & 405 \\
\hline CP4 & $5 / 95$ & 4.35 & 2.08 & - & 101 & 396 \\
\hline $\mathrm{PSt}^{f}$ & - & - & - & - & 100 & 396 \\
\hline
\end{tabular}

Abbreviations: GPC, gel permeation chromatography; LALLS, laser light scatting;

$M \mathrm{n}$, number-average molecular weight; $M \mathrm{w}$, weight-average molecular weights; $M \mathrm{w}^{*}$, absolute weight-average molecular weight; $T \mathrm{~d}_{10}$, temperature at $10 \%$ weight loss; Tg, glass transition temperature.

aThe molar ratio of monomer $\mathbf{5}$ and styrene in the polymerization.

${ }^{\mathrm{b}} \mathrm{Mn}$ and $M_{\mathrm{w}}$ were determined by GPC based on polystyrene standards (eluent: tetrahydrofuran). ${ }^{c} M w^{*}$ was determined by LALLS method based on polystyrene standards (eluent:

tetrahydrofuran).

${ }^{\mathrm{d}} \mathrm{Tg}$ was determined by differential scanning calorimetry at $10^{\circ} \mathrm{C}$ per min on the third heating

${ }^{\mathrm{e}} \mathrm{T} \mathrm{d}_{10}$ was determined by TG-DTA.

fPolystyrene standard ( $M \mathrm{w}=43900)$, purchased from Tosoh Co., Ltd.

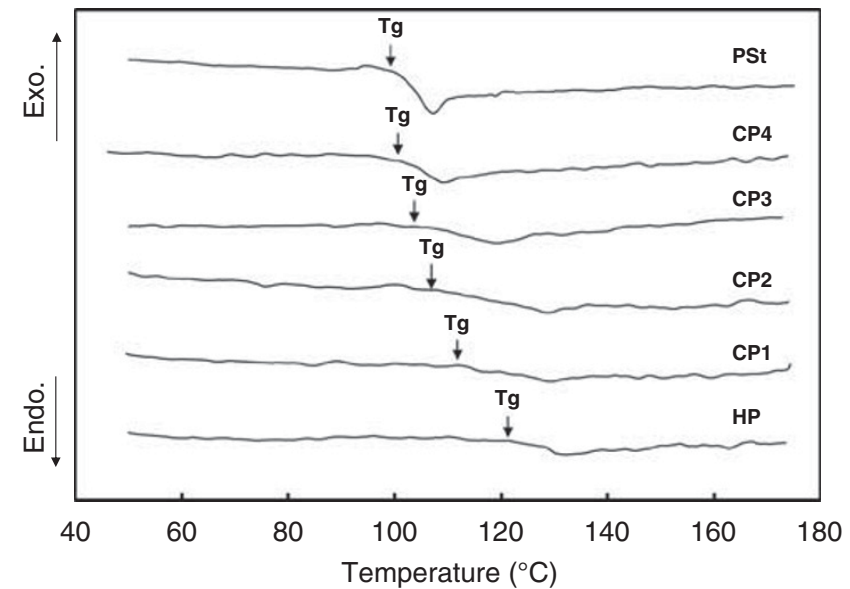

Figure 1 Differential scanning calorimetry curves of the polymers at $10^{\circ} \mathrm{C}$ per min on the third heating scan.

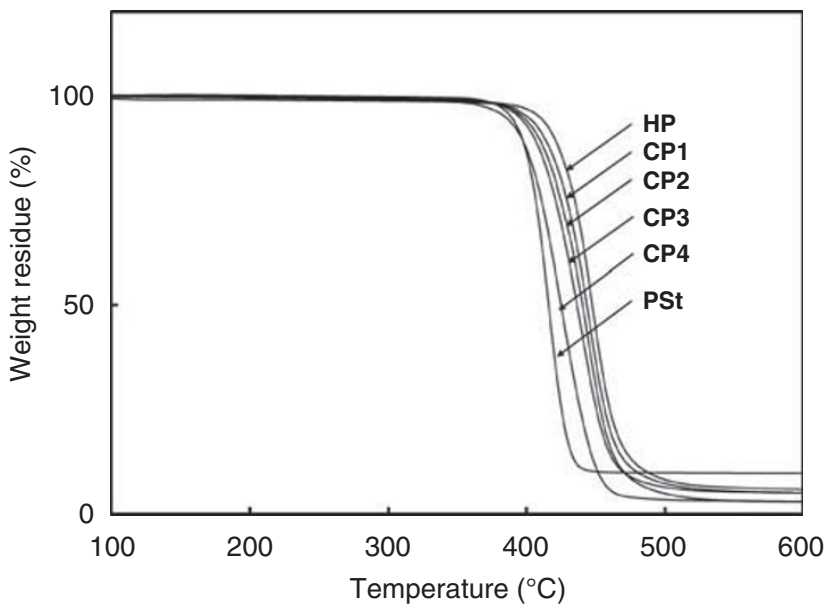

Figure 2 Thermal gravimetric analysis curves of the polymers at $10^{\circ} \mathrm{C}$ per $\min$ in a $\mathrm{N}_{2}$ flow.

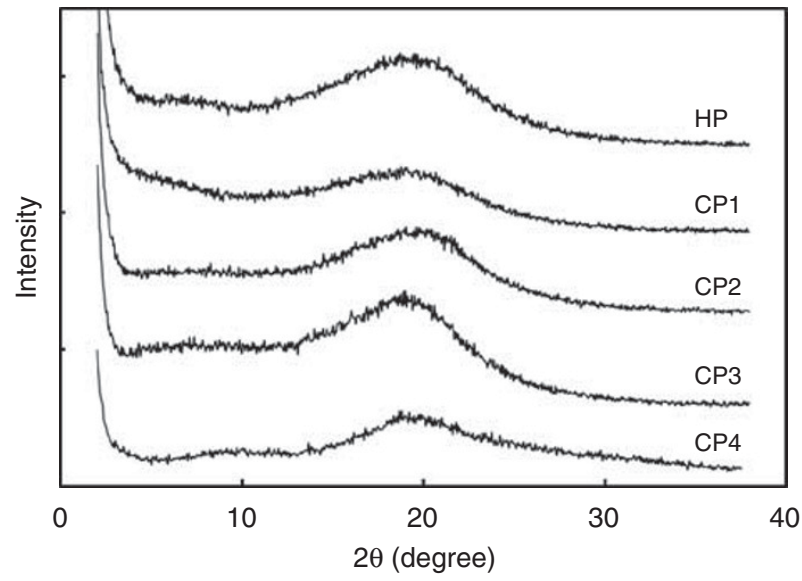

Figure 3 X-ray diffraction patterns of the polymers.

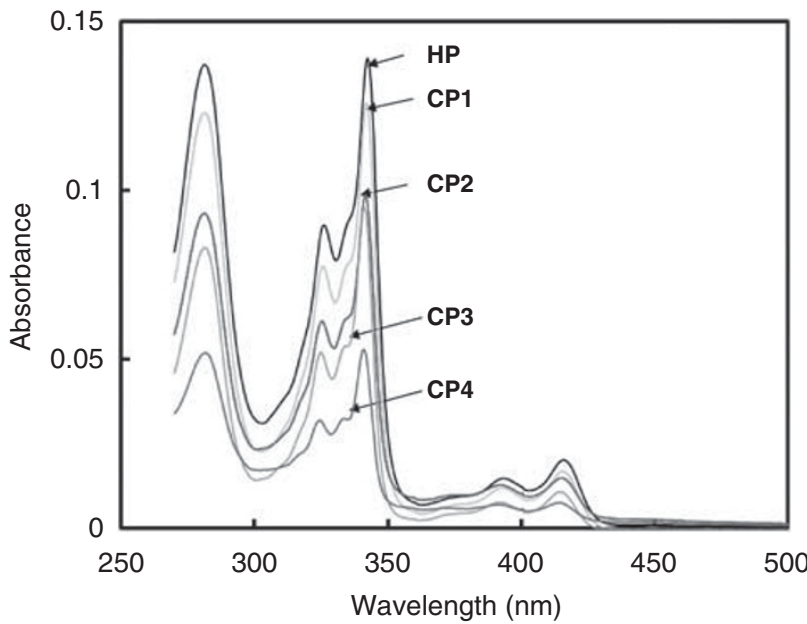

Figure 4 Ultraviolet-visible absorption spectra of the solutions of polymers containing the indolo[3,2-b]carbazole moiety. The concentrations of the polymer solutions were $0.48 \mathrm{gl}^{-1}$ in tetrahydrofuran.

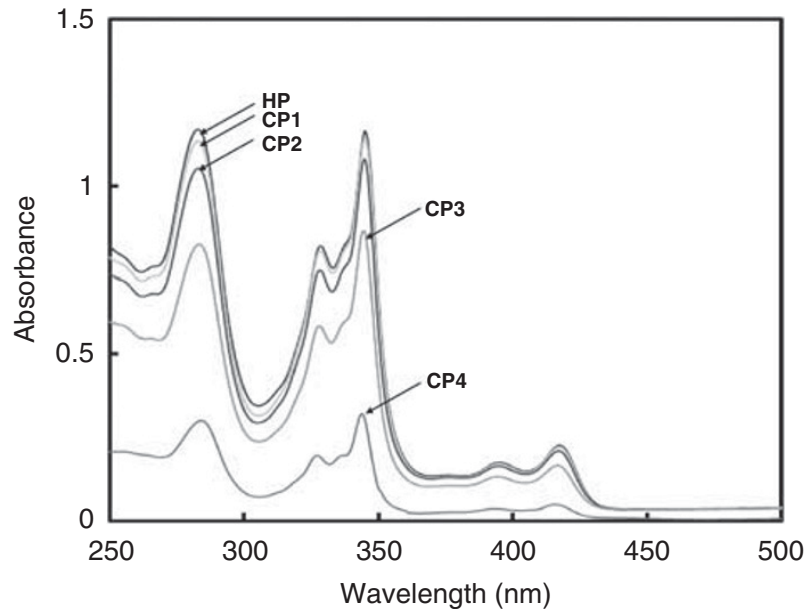

Figure 5 Ultraviolet-visible absorption spectra of the films of polymers containing the indolo[3,2-b]carbazole moiety. The thickness of the films was ca. $150 \mathrm{~nm}$ on quartz substrates. 


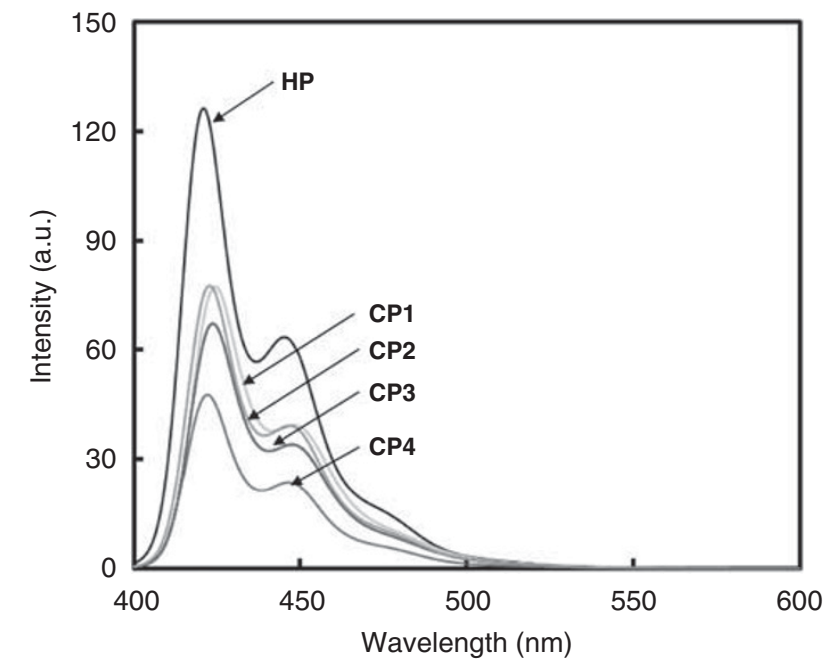

Figure 6 The photoluminescence spectra of the solutions of polymers containing the indolo[3,2-b]carbazole moiety. The excitation wavelength was $341 \mathrm{~nm}$ for all polymers, and the concentration of the polymer solutions was $0.48 \mathrm{gl}^{-1}$ in tetrahydrofuran.

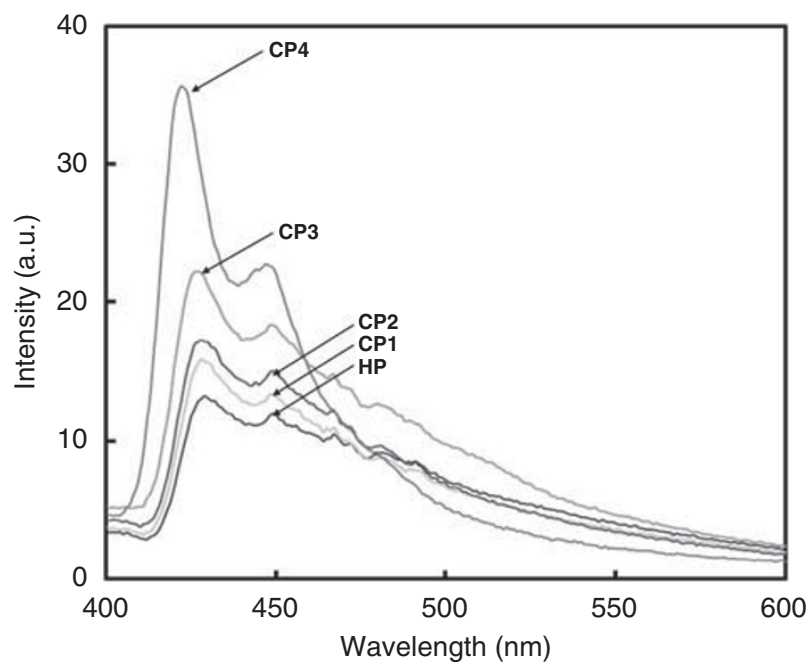

Figure 7 The photoluminescence spectra of the films of polymers containing the indolo[3,2-b]carbazole moiety. The excitation wavelength was $345 \mathrm{~nm}$ for HP, CP1, CP2 and CP3 and $344 \mathrm{~nm}$ for CP4. The thickness of the films was ca. $150 \mathrm{~nm}$ on quartz substrates.

more, the peak pattern of the CP4 film was similar to that of the CP4 solution, but the peak patterns of the CP1-3 and HP films were different from those of the solutions. The maximum wavelengths of photoluminescence of the CP1-3 and HP films were observed in the range of $425 \mathrm{~nm}$ to $450 \mathrm{~nm}$, with a long tail extending beyond $600 \mathrm{~nm}$. Cho et al. ${ }^{33}$ have reported that a similar tendency was observed in poly-4-(9-carbazolyl)methylstyrene film, which was probably due to the excimer formation of the carbazole moiety. Consequently, it is proposed that the increase of the INC component in the polymer caused concentration quenching due to the condensation of intermolecular interaction between the INC components, which have stronger interactions than the carbazole component. In contrast, the decrease of the INC component in the polymer led to lower intermolecular interactions of INC components and increased the photo- luminescence intensities of the polymer films. Actually, in the case of the CP4 film, which had the lowest content of INC units, 35 wt.\%, two maximum photoluminescent peaks were clearly observed at $423 \mathrm{~nm}$ and $448 \mathrm{~nm}$, and the peak intensity of the CP4 film at around $423 \mathrm{~nm}$ was remarkably stronger than that of the other films.

\section{CONCLUSION}

A new synthetic route for INC-containing monomers was established, and polystyrene-based copolymers containing the INC moiety were prepared by radical polymerization. The copolymers obtained were amorphous and exhibited higher thermal stability than polystyrene. Therefore, the INC moiety improved the thermal stability due to the strong interaction between the planer INC groups. In the ultraviolet-visible absorption spectra, the peak intensities of the solutions and films increased with increasing INC monomer units. On the contrary, the photoluminescence spectra of the polymer solutions and films indicated the opposite tendency. The photoluminescence intensities of the copolymer films decreased with increasing INC content in the copolymer, although the intensities in the copolymer solutions increased according to the INC content due to the concentration quenching in polymer films by the intermolecular interaction between the INC components at high concentrations.

The fundamental performance of copolymers containing the INC moiety as a side chain was described in this paper. In particular, the copolymer CP4 exhibited high emission and good film-forming ability, although the INC content was $35 \mathrm{wt} . \%$. In our previous work, we estimated the photoluminescence quantum yields of INC and alkylated INC to be 0.50 and $0.52-0.54$, respectively. ${ }^{30}$ Therefore, copolymers containing the INC moiety are candidates for photonic or electronic materials in the emission or carrier-transporting layer of electroluminescence devices.

\section{CONFLICT OF INTEREST}

The authors declare no conflict of interest.

1 Shirota, Y., Kinoshita, M., Noda, T., Okumoto, K. \& Ohara, T. A novel class of emitting amorphous molecular materials as bipolar radical formants: 2-\{4-[bis(4-methyl phenyl)amino]phenyl\}-5-(dimesitylboryl)thiophene and 2-\{4-[bis(9,9-dimethylfluor enyl)amino]phenyl\}-5-(dimesitylboryl)thiophene. J. Am. Chem. Soc. 122, 11021-11022 (2000).

2 Tonzola, C. J., Alam, M. M., Kaminsky, W. \& Jenekhe, S. A. New n-type organic semiconductors: synthesis, single crystal Structures, cyclic voltammetry, photophysics, electron transport, and electroluminescence of a series of diphenylanthrazolines. J. Am. Chem. Soc. 125, 13548-13558 (2003).

3 Kolosov, D., Adamovich, V., Djurovich, P., Thompson, M. E. \& Adachi, C. 1,8-Naphthalimides in phosphorescent organic LEDs: the interplay between dopant, exciplex, and host emission. J. Am. Chem. Soc. 124, 9945-9954 (2002).

4 Sakamoto, Y., Komatsu, S. \& Suzuki, T. Tetradecafluorosexithiophene: the first perfluorinated oligothiophene. J. Am. Chem. Soc. 123, 4643-4644 (2001).

5 Sakamoto, Y., Suzuki, T., Miura, A., Fujikawa, H., Tokito, S. \& Taga, Y. Synthesis, characterization, and electron-transport property of perfluorinated phenylene dendrimers. J. Am. Chem. Soc. 122, 1832-1833 (2000).

6 Bao, Z., Lovinger, A. J. \& Brown, J. New air-stable $n$-channel organic thin film transistors. J. Am. Chem. Soc. 120, 207-208 (1998).

7 Meng, H., Bendikov, M., Mitchell, G., Helgeson, R., Wudl, F., Bao, Z., Siegrist, T., Kloc, C. \& Chen, C. Tetramethylpentacene: remarkable absence of steric effect on field effect mobility. Adv. Mater. 15, 1090-1093 (2003).

8 Yasuda, T., Goto, T., Fujita, K. \& Tsutsui, T. Ambipolar pentacene field-effect transistor with calcium source-drain electrodes. Appl. Phys. Lett. 85, 2098-2100 (2004).

9 Briseno, A. L., Mannsfeld, S. C. B., Ling, M. M., Liu, S., Tseng, R. J., Reese, C., Roberts, M. E., Yang, Y., Wudl, F. \& Bao, Z. Pattening organic single-crystal transistor arrays. Nature 444, 913-917 (2006).

10 Katz, H. E. \& Bao, Z. The physical chemistry of organic field-effect transistors. J. Phys. Chem. B 104, 671-678 (2000). 
11 Thompson, B. C., Kim, Y. \& Reynolds, J. R. Spectral broadening in MEH-PPV: PCBM-based photovoltaic devices via blending with a narrow band gap cyanovinylene-dioxythiophene polymer. Macromolecules 38, 5359-5362 (2005).

12 Sun, Y., Ma, Y., Liu, Y., Ling, Y., Wang, Z., Wang, Y., Di, C., Xiao, K., Chen, X., Qiu, W., Zhang, B., Yu, G., Hu, W. \& Zhu, D. High-performance and stable organic thin-film transistors based on fused thiophenes. Adv. Funct. Mater. 16, 426-432 (2006).

13 Miao, Q., Chi, X., Xiao, S., Zeis, R., Lefenfeld, M., Siegrist, T., Steigerwald, M. L. \& Nuckolls, C. Organization of acenes with a cruciform assembly motif. J. Am. Chem. Soc. 128, 1340-1345 (2006).

14 Wu, Y., Li, Y., Grarder, S. \& Ong, B. S. Indolo[3,2-b]carbazole-based thin-film with high mobility and stability. J. Am. Chem. Soc. 127, 614-618 (2005).

$15 \mathrm{Li}, \quad$ Y., Wu, Y. \& Ong, B. S. Polyindolo[3,2-b]carbazoles: a new class of p-channel semiconductor polymers for organic thin-film transistors. Macromolecules 39, 6521-6527 (2006).

16 Wakim, S., Bouchard, J., Simard, M., Drolet, N., Tao, Y. \& Leclerc, M. Organic microelectronics: design, synthesis, and characterization of 6,12-dimethylindolo[3,2b]carbazoles. Chem. Mater. 16, 4386-4388 (2004).

17 Belletete, M., Blouin, N., Boudreault, P. T., Leclerc, M. \& Durocher, G. Optical and photophysical properties of indolocarbazole derivatives. J. Phys. Chem. A. 110, 13696-13704 (2006).

$18 \mathrm{Gu}$, R., Hameurlaine, A. \& Dehaen, W. Facile one-pot synthesis of 6-mono substituted and 6,12-disubstituted 5,11-dihydroindolo[3,2-b]carbazoles and preparation of various functionalized derivatives. J. Org. Chem. 72, 7207-7213 (2007).

$19 \mathrm{Li}$, Y., Wu, Y., Gardner, S. \& Ong, B. S. Novel peripherally substituted indolo $[3,2-b]$ carbazoles for high-mobility organic thin-film transistors. Adv. Mater. 17, 849-853 (2005).

$20 \mathrm{Gu}$, R., Hecke, K. V., Meervelt, L. V., Suzanne Toppet, S. \& Dehaen, W. Oxidative reactions of 6-pentyl indolo[3,2-b]carbazole: Formation of novel C-C and C-N coupled dimmers. Org. Biomol. Chem. 4, 3785-3789 (2006).

$21 \mathrm{Hu}$, N., Xie, S., Popovic, Z., Ong, B. \& Hor, A. 5,11-Dihydro-5,11-di-1-naphthylindolo[3,2-b]carbazole: Atropisomerism in a novel hole-transport molecule for organic light-emitting diodes. J. Am. Chem. Soc. 121, 5097-5098 (1999).
22 Boudreault, P. T., Wakim, S., Tang, M. L., Tao, Y., Bao, Z. \& Leclerc, M. New indolo [3,2-b]carbazole derivatives for field-effect transistor applications. J. Mater. Chem. 19, 2921-2928 (2009).

23 Velasco, D., JankausKas, V., Stumbraite, J., Grazulevicius, J. V. \& Getautis, V. Indolo[3,2-b]carbazole derivatives as hole transporting materials for electrophotography. Synthetic Metals 159, 654-658 (2009).

24 Gu, R., Robeyns, K., Meervelt, L. V., Toppet, S. \& Dehaen, W. Facile synthesis of novel indolo[3,2-b]carbazole derivatives and a chromogenic-sensing 5,12-dihydroindolo[3,2-b]carbazole. Org. Biomol. Chem. 6, 2484-2487 (2008).

25 Guo, Y., Zhao, H., Yu, G., Di, C., Liu, W., Jiang, S., Yan, S., Wang, C., Zhang, H., Sun, X., Tao, X. \& Liu, Y. Single-crystal microribbons of an indolo[3,2-b]carbazole derivative by solution-phase self-assembly with novel mechanical, electrical, and optical properties. Adv. Mater. 20, 4835-4839 (2008).

26 Levesque, I., Bertrand, P., Blouin, N., Leclerc, M., Zecchin, S., Zotti, G., Ratcliffe, C. I., Klug, D. D., Gao, X., Gao, F. \& Tse, J. S. Synthesis and thermoelectric properties of polycarbazole, polyindolocarbazole, and polydiindolocarbazole derivatives. Chem. Mater. 19, 2128-2138 (2007).

27 Blouin, N., Leclerc, M., Vercelli, B., Zecchin, S. \& Zotti, G. Optical, electrochemical, magnetic, and conductive properties of new poly(indolocarbazole-alt-bithiophene)s. Macromol. Chem. Phys. 207, 175-182 (2006).

28 Kirkus, M., Grazulevicius, J. V., Grigalevicius, S., Gu, R., Dehaen, W. \& Jankauskas, V. Hole-transporting glass-forming indolo[3,2-b]carbazole-based diepoxy monomer and polymers. Eur. Polymer J. 45, 410-417 (2009).

29 Lu, J., Liang, F., Drolet, N., Ding, J., Tao, Y. \& Movileanu, R. Crystalline low band-gap alternating indolocarbazole and benzothiadiazole-cored oligothiophene copolymer for organic solar cell applications. Chem. Commun. 5315-5317 (2008).

30 Akimoto, M., Kawano, T., Nagase, Y., Kawamoto, M. \& Wada, T. Synthesis and photonic properties of indolocarbazole derivaties. Trans. Mater. Res. Soc. Jpn. 34, 141-144 (2009).

31 Bergman, J. Condensation of indole and formaldehyde in the presence of air and sensitizers. Tetrahedron 26, 3353-3355 (1970).

32 Yudina, L. N. \& Bergman, J. Synthesis and alkylation of indolo[3,2-b]carbazoles. Tetrahedron 59, 1265-1275 (2003).

33 Cho, Y., Kim, S., Ihn, C. \& Lee, J. Anionic polymerization of 4-(9-carbazolyl)methylstyrene. Polymer 42, 7611-7616 (2001). 